\title{
Silence of Mauá: An Atmospheric Ethnography of Urban Sounds
}

Jean-Paul Thibaud

\section{Mauá, according to ambiance}

In 2015 a group of Brazilian and French researchers carried out a field investigation at the Condominío Barão de Mauá. ${ }^{1}$ The condominium is located in the town of Mauá, some 30 kilometres from São Paulo, Brazil. The complex, built in 1996, consists of 54 buildings housing about 7,000 people and stands on land contaminated by industrial waste buried there. The residents became aware of the contamination in April 2000 when an explosion occurred during maintenance work on one of the pumps for the condominium's underground water reservoirs. It was probably caused by the presence of methane gas. A worker was killed in the explosion, another one badly burned. Legal proceedings have been underway ever since, leaving the residents exposed to the risk of contamination by carcinogenic substances and another explosion.

\footnotetext{
1 This research is part of a dual framework: a CNRS program PEPS FaiDoRA "Faibles Doses, Risques, Alertes" (CRESSON-UMR AAU, France) and a FAPESP program "Da Cominicação de Riscos à Cultura de Risco" (CETESB, Brazil). The research team was composed of Silvia Regina Burzaca, Alvaro Florentino da Silva Jr, Anali Espindola de Campos, Sylvain Dubert, Carolina Poletti Maestri Ferreira, Jacques Lolive, Cintia Okamura, Norma Lucia Porto, Thiago Rigui, Patrick Romieu, Maria de Lourdes Pinheiros Simões, Jean-Paul Thibaud, and Nicolas Tixier.
} 


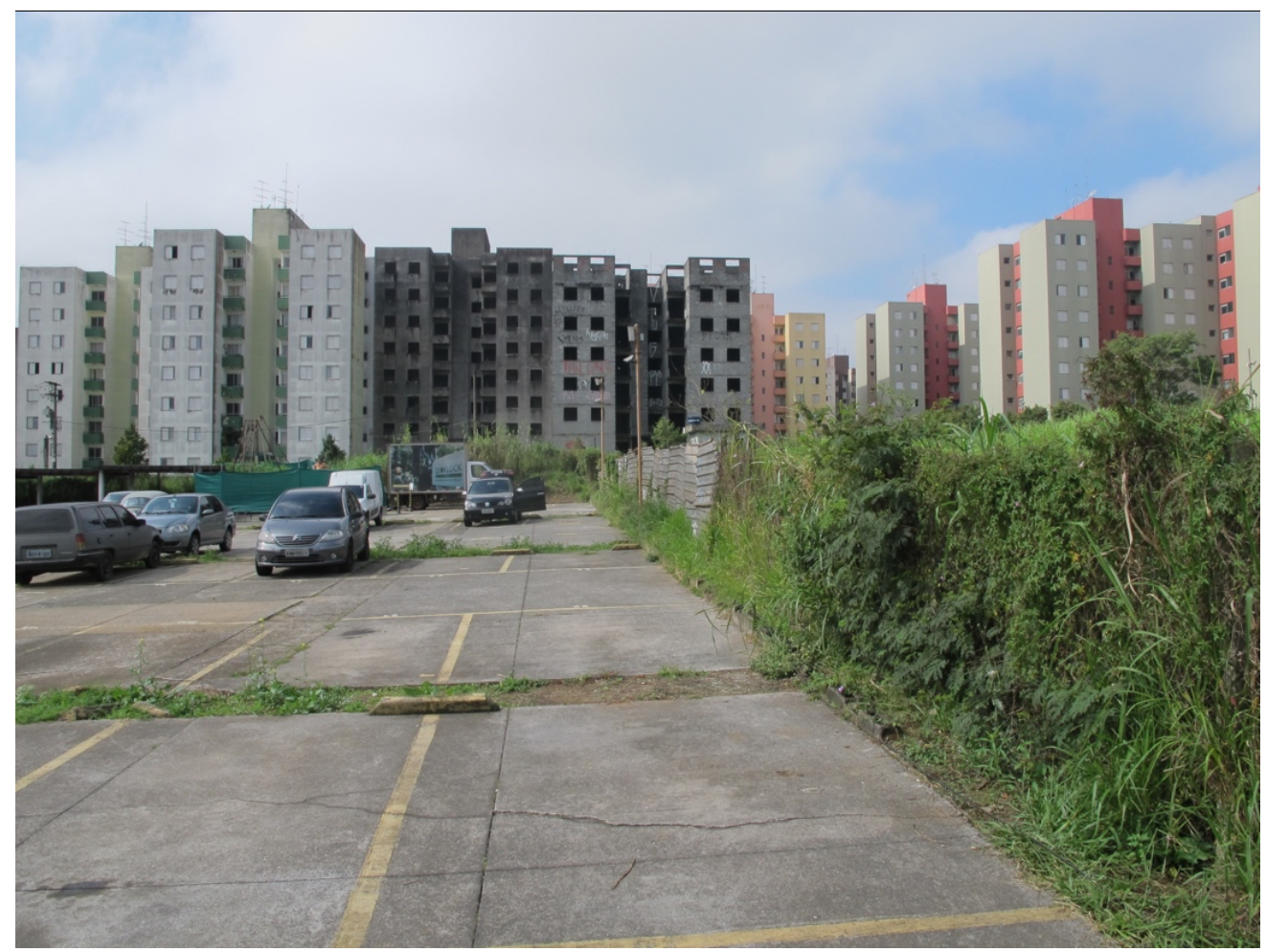

A view of Condominío Barão de Mauá, photo by Sylvain Dubert

The purpose of the field work was to test the notion of risk ambiance and understand how one can go on living in a contaminated environment of this sort. We posit that a risk-prone environment is embodied in specific ambiances and that it lends itself to particular sensory experiences that can be documented, providing a suitable methodology can be found. Our aim is to focus on the emergence of a resident sensibility to risk, investigate what might constitute a risk-sensitive culture and highlight the socio-political consequences of day-to-day vulnerability under conditions of this sort. In preparation for this methodological experimentation, we investigated ongoing controversy on the situation, in order to understand what was at stake for the contaminated area, go back over its history and public life, pinpoint the various players involved in the controversy and clarify the context of our field investigation. $^{2}$

\footnotetext{
2 This approach was lead in particular by Jacques Lolive and Cintia Okamura. See: Jacques Lolive, Cintia Okamura "Quelle communication pour la société du risque ? Des expérimentations méthodologiques pour développer une culture du risque", Cahiers de géographie du Québec, 2016, 60 (169), p. 152-172. <hal-01568178> <http://www.cgq.ulaval.ca/textes/vol_60/no169/Som169.html>
} 
To approach Condominío Barão de Mauá in terms of ambiance entails studying the sensory contexts of the lived-in space and how it is experienced, practiced and perceived day-to-day. As a first approximation, an ambiance may be defined as a space-time experienced in sensory terms. ${ }^{3}$ It is always situated (even if its outlines are fuzzy), it activates all the modalities of perception (sound, light, smell, heat and so on) and proceeds by weaving together the material properties of an environment, social practices, resident memories and narratives, and the affective tonalities that color a situation. If ambiance gives us a grasp of the quality, singularity and tonality of a situation, how does it enable us to experience a risk-prone territory? What can we learn through ambiental awareness? The present chapter explores the possible make-up of an inquiry in ambient mode, in short investigating risk by way of ambiance, according to ambiance and its sonorities.

\section{An atmospheric ethnography}

For this field investigation we carried out a five-day experiment in methodology that we might describe as atmospheric ethnography. ${ }^{4}$ Before presenting our investigatory approach in greater detail, I should underline the three key features of ambiance that underpin this field action. Firstly, ambiance proceeds from a 'pervasive field', which places the emphasis on immersion rather than a face-to-face relation. With ambiance we are steeped in a sensory milieu which wholly envelopes us at all times. Of the order of feeling as much as perceiving, ambiance puts us in contact with the globality of a situation, by paying full attention to floating attentions, peripheral perceptions and the fringes of experience. Secondly, ambiance proceeds from a 'permanent

\footnotetext{
${ }^{3}$ Jean-Paul Thibaud "The Sensory Fabric of Urban Ambiances". Senses and Society. Volume $6, n^{\circ} 2,2011$, p. 203-215. For a more extensive and thorough approach of ambiance, see Jean-Paul Thibaud En quête d'ambiances. Eprouver la ville en passant. Genève, MétisPresses, 2015.

4 This atmospheric ethnography can be related to two major trends of research: on the one hand 'atmospheric methods', on the other hand 'sensory ethnography'. Concerning the first approach, see Ben Anderson and James Ash "Atmospheric Methods". In: Philipp Vannini (ed.) Non-Representational Methodologies: ReEnvisioning Research. London, Routledge, 2015, p. 34-51. See also Sara Asu Schroer and Suzanne B. Schmitt (eds.) Exploring Atmospheres Ethnographically. Routledge, 2017. Concerning the second approach, see François Laplantine Le social et le sensible, introduction à une anthropologie modale. Paris, Téraèdre, 2005. See also Sarah Pink Doing Sensory Ethnography. London, Sage, 2009.
} 
background', a basso continuo on which the world takes on a certain physiognomy, a certain affective tonality. In other words ambiance sets the tone for situations and everyday territories. Rooted in the habits and practices of residents, it makes the forms of social life perceptible and embodies ways of being together in a particular setting. Thirdly, ambiance proceeds from an 'unobtrusive pregnancy'. It gains consistency through low-intensity phenomena, so slight as often to be imperceptible. Proceeding most of the time by light touches, small inflections and micro-phenomena, it is of the order of the infra and of little perceptions, so tiny and mixed up with each other that they are hard to perceive distinctly ${ }^{5}$. These three characteristics pervasive, habitual and unobtrusive - make ambiance a particularly relevant notion for understanding how risk-prone situations impregnate resident experience.

Our proposal for an atmospheric ethnography consists in coming as close as possible to lived situations in order to gain access to the discreet expressions of resident sensibility, to the pervasive sensations of the ambient environment, the everyday background to the perceptions and practices of residents. In so doing we aim to capture and describe what relates to sensory perceptions, material traces and social memory, everyday gestures, ordinary words, and ways of being together. This exploratory approach seeks to study the embodied, situated, enacted and shared nature of the sensory relation which residents entertain with their home. The main difficulty here is touching what usually passes unnoticed, barely voiced, the thousand and one little signs that play a part in everyday sensory life. It should be immediately apparent that resorting to the conventional methods of inquiry is of no use here.

Our investigatory approach is designed to make us as amenable as possible to all we encounter on the spot. Rather than starting from any prior assumptions or preconceived methodological guidelines, our purpose is to develop a posture of openness to our surroundings and adopt an attitude of 'disengagement' or 'letting go', coming as close as possible to a floating ear and unfocussed attention. We refer to this as atmospheric ethnography because it is a matter of experimenting with a device for paying attention to the pervasive. To do this we carry out a form of inquiry that is both immersed, plural, collective and evolving.

\footnotetext{
${ }^{5}$ A theory of 'little perceptions' (petites perceptions) has been developed by Gottfried Wilhelm Leibniz in his preface of New Essays Concerning Human Understanding. Cambridge, Cambridge University Press, 1996 [1704]. A very stimulating comment has been devoted to this notion by Gilles Deleuze Le pli. Leibniz et le baroque. Paris, Minuit, 1988.
} 
- Our inquiry is immersed because it uses in situ investigation, right in the middle of the Barão de Mauá housing complex. In so doing we aim to take seriously our bodily presence and our own capacity to be affected by an environment of this sort. The investigators experience the ambiances of the Condominío, sense their effect on themselves, and are transformed through contact with them. A sharable experience is thus possible for investigators and residents.

- Our inquiry is plural, drawing on various lightweight yet complementary approaches. It involves techniques as varied as ethnographic observation, commented walks, floating listening by individuals or groups, audio recordings with sonic reactivation, photographic drifting, organized encounters with residents and a joint logbook. ${ }^{6}$ Such variety helps to broaden the field of perception while introducing variations to modes of attention. Resonances take place between open approaches that initiate the investigation (drifting, floating listening, informal observations and encounters) and more framed approaches that specify it (commented walks, sonic reactivations, in-situ collective listening).

- Our inquiry is collective ${ }^{7}$, bringing into play three dynamics, one inside the group of investigators, one among residents, and one between residents and investigators. In this context the joint logbook plays a key role. It is kept on a day-to-day basis, fed by regular encounters and discussions between all the investigators (all sessions are recorded). Each investigator's experiences are systematically shared and debated in such a way as to articulate and give an account of the atmospheric qualities of the place.

- Our inquiry evolves, lending itself to all sorts of modalization, reconfiguration and branching, as encounters with residents and discussion among investigators progress. Regular debate on investigators' respective experiences and recurrent interplay between collective analysis and field investigation transform, with each day that passes, the sensibility to the risk-prone environment. A key feature of the investigatory toolkit, the joint logbook, enables us to register the ongoing process of exploring, making explicit and sedimenting knowledge.

\footnotetext{
${ }^{6}$ Some of those methods are described in Michèle Grojean and Jean-Paul Thibaud (eds.) L'espace urbain en méthodes. Marseille, Parenthèses, 2001.

7 Collective ethnography is starting to develop in contemporary social sciences. See Reuben A. Buford May and Mary Pattillo-McCoy "Do You See What I See? Examining a Collaborative Ethnography", Qualitative Inquiry, Volume 6 Number 1, 2000, p. 6587. See also Gilles Laferté "Retours d'expériences. Plaidoyer pour l'ethnographie collective", ethnographiques.org, Numéro 32, septembre 2016.
} 
This proposal for an atmospheric ethnography may be referred to as "ambulatory knowledge" described by William James. ${ }^{8}$ Its purpose is to explore how a group of investigators gradually allows itself to be impregnated and transformed by the ambiances of a place, in such a way as to reveal its tonality and agency.

\section{Listening to an enigmatic silence}

The ambiances of the Barão de Mauá condominium are largely impregnated by the risk of contamination. Sometimes this is manifest and very visible, witness the abandoned buildings standing empty after construction work suddenly stopped. They prompt a sense of desolation, conjuring up images of a territory laid waste by war or natural disaster. This feeling is reinforced by the fact that the residents do all they can to care for their living space, paying great attention to its upkeep. In other cases the impression is less obvious, more secret, as with the presence of odors which permeate the housing complex, a nagging reminder of the contaminated soil, the smell of the air and earth, more noticeable at some times than others. According to the residents the pregnancy of this smell varies a great deal depending on the weather, more perceptible when it rains and the temperature rises, emanating from the ground.

But at an early stage we encountered an enigma: the strange sense of silence gripping the condominium. This prompted us to investigate the sounds of the site. The atmospheric ethnography then turned into a shared listening to local ambiances. From the outset, a collective impression emerged from our explorations and discussions, but it struggled to express itself clearly and was stated in various ways. At a loss for words our exchanges hesitated on how to translate this shared yet largely elusive sensation. Our joint logbook helped us afterwards in reconstituting the progress of our listening, gradually bringing us into resonance with Barão de

8 William James The Meaning of Truth: A Sequel to 'Pragmatism'. The Floating Press, [1909] 2010. William James makes a distinction between "ambulatory knowledge" and "saltatory knowledge": "Now the most general way of contrasting my view of knowledge with the popular view (which is also the view of most epistemologists) is to call my view ambulatory, and the other view saltatory; and the most general way of characterizing the two views is by saying that my view describes knowing as it exists concretely, while the other view only describes its results abstractly taken" ( $p$. 107). Ambulatory knowledge takes into consideration intersubjective experience, intermediate experiential steps and is played out step-by-step. 
Mauá. As part of its regular meetings, the group undertook a phenomenological description. The polyphony of remarks, comments, translations and reformulations that unfolded among the investigators sought to describe this experience as closely as possible, gradually attuning our collective ear to the neighborhood and even shifting the direction of our inquiry. An interaction loop was set up connecting our lived, in situ experience and a collective return on experience. On the one hand field work enabled us to flesh out our sonic experience, gathering the accounts of residents and additional ethnographic observations, test new forms of attention and in-situ listening modes, and validate previously shared descriptions. On the other hand group meetings enabled us better to share individual experiences, gradually composing a common way of listening to situations, opening up new ideas for description and interpretation; they also prepared for further site visits. In this way we tested in two ways the enigmatic silence that became a key motif in our inquiry: through a collective description, and through an ongoing in situ investigation. It took all the available time of our stay to gradually come close to this enigmatic silence, which proved remarkably revealing as to the singular condition of the neighborhood. ${ }^{9}$

Below is a polyglot composition of excerpts from the joint logbook. All the investigators contributed to this log, which also takes the form of a collective composition in the making. ${ }^{10}$ The sequence of these extracts follows the timeline of the log and reflects the verbal dynamics between the investigators. Some topics recur during our exchanges and are reformulated in the course of meetings; various key ideas emerge gradually.

\section{Polyglott recomposition of excerpts from the joint logbook}

\section{the silence of absence}

...a risk territory cannot be considered solely from the angle of risk... there are inhabitants, there are people living and it is a living environment... therefore it also means care given to the place where we live...

\footnotetext{
${ }^{9}$ This task greatly benefited from the auditory skills of Patrick Romieu and Nicolas Tixier.

10 Most discussions were in French, with some input in Portuguese and more rarely in English. Cintia Okamura, a Brazilian researcher on the team who speaks perfect French, produced a translation. It would be worth devoting a whole article to the question of translation as part of investigatory methodology of this sort.
} 
... yes, but we don't hear it... I barely heard any voices... I heard very very few inhabitants...

... indeed... I noticed the very very calm dimension of the neighborhood... at the beginning it was a peaceful quiet... and then as I walked I noticed something "between the peaceful quiet and the silence of desolation"...

... Anali says that it's the second time she comes here, and that she also has this sensation that... uh, the people... it's lacking some people...

birds and planes

... I was very attentive to the transition between interior and exterior, which happened for me with the soundscape and the birds...

... I'd just add the... the planes in the landscape, they are really present...

noiseless interior

... it depends a lot on the trips that are made and there is... it's true, there's much less noise inside the condominium than outside...

... when we came down... we walked along the stream and there is another neighborhood... there are small houses with fencing at the entrance, and at this point there is a lot of noise... it's much more lively, we found noise, barking dogs, people speaking loudly, music... we found a lot livelier, a lot louder... just like we expected... the condominium is still much more silent than the average...

static and lifeless

... here inside, it's rather static... In São Paulo, in a Condominío, you can hear the TV, smell food... here, you know that dwellers live here because you can see clothes, but it's static... there are no children's voice...

... when you enter the apartments, you start to see life... but outside, no...

... the first impression, that's the buildings... abandoned... after talking to the manager... today, of course, there's the rain... but it's lacking a welcoming place for people, you see...

... outside, a lot of movement... here... silence...

absence of garden

... actually, I looked for clues from the absence of clues... the things that wouldn't be here, actually... in particular the gardens... would there be vegetable gardens... I didn't see any anywhere... in many places, I thought to myself "oh, here maybe there'll be one" because it looked like ideal conditions for a garden, vegetable garden, family garden...

... yes, there was this story... they tried to create gardens but actually, because of the contamination, the plants, well...

vacant apartments? 
... there's still some... there is a lot of vacancy still... which means that the buildings that are inhabitable are not completely full...

... some people are gone, you know... some are gone, and others have leased again...

... which could explain in part the silence...

the 2000 explosion

... we were with a dweller from step 4... that's exactly where the accident happened... his name is Elton... and so he was there at the time of the explosion.. he was at his place when he heard a... boom! ... the explosion... and because there's the petrochemical hub (not far) there are always explosions... and so he first thought that it was the petrochemical hub... and then he saw the two people that they... that were injured... he saw a few people screaming... and then he went down to see and found the one that was completely burned...

everything is stuck

...everything here is stuck... for example they wanted to build a place for parties, but they can't because it's stuck... they can't improve the buildings because everything is stuck...

... there is a problem because she wanted the approval from CETESB (Environmental Agency of the State of São Paulo) to build a garage... It's the CETESB that has to give its approval, but the thing is that we can't perforate... indeed there's always the threat of explosion, but, well, since we don't dare perforating, drilling...

a place without rhythm

... there were several people who were coming by car, were repairing their cars, two young girls who were playing in the play area and whose phones were used as speakers for music... so, all I'm talking about has a sound dimension....

... here, it was... even with the sound, it was super silent and quiet and we couldn't hear the city in the background... I mean, in fact, it really feels like there's a rhythm set by the city nearby and like on site we have the sounds of punctual events, but there's no rhythm to this place...

paralysis effect ... and so if I understand correctly, once more, since everything seems impossible. the paralysis effect we mentioned yesterday... this paralysis effect we mentioned yesterday about sensory experiences... here is translated similarly in the possibilities of dwelling actions, are we clear?

... yes, this isn't simply the impression given by being conscious of the risks, but objectively there's a paralysis of any development... and that paralysis, it can't 
not have an effect on people's state of mind, on mentalities, all of that... yes, so this statement is very interesting...

... for example, there are children, there are women who are doing stuff, there are young girls who are playing... that's what should punctuate the condominium... there a life that should... that we should be able to hear...

... there's also an abandoned basketball court because it was in the condominium that stopped...

the outside rhythm

... you said that the small sounds that you have... whereas there was sound... that the rhythm was coming from the outside, the horizon.

... but instead of that, if you want, it's more partial than that, less strong... it's more... we can feel it less... what you can feel strongly, it's in the background, the big boulevard, you know... that drives fast, the big petrochemical hub and all the little houses we saw, too, that are on the riverside, and that's what creates animation... whether it is about colours, living things...

the milieu is lacking

... in fact, the idea of... in the sound field, there are three rather simple categories that are the... the audible signal... so that's an audible signal (knock knock on the table)... the soundscape, which is when we're talking... and then the background sound, maybe the wind tunnel, the outside noise... here it's like there is the audible signal, which means the people when they're doing something we can hear... the car, when it's driving around, we can hear it... people when they slam the door or when they play football, we can hear... and then, there is the background sound, which is the city in the background, which is another rhythm, very diff... diffuse, visual, sound... but the soundscape is lacking...

... we're not... we're not into, except in the silence, into... into a soundscape

pumping effect

... the nearby space is... the nearby space is almost a desert... there's a desertification of the nearby space of... of the body...

... the activities are discreet, in terms of space discretion...

... it's pumped, it's completely pumped by a superior ambiance that is given by the... I think there's a pumping effect... like a blotting paper, the sound is blotted...

crushing feeling

... we already said it yesterday, the very strong presence of airplane, either during take-off or landing... I didn't check that... I can't tell, but they're flying low, and so they're creating a sound ceiling that is very very low... It feels like being crushed by the ceiling... but at the same time, am I completely trapped? Yes and 
no. Why? Because I can find something that Nicolas already mentioned... that are the sound horizon in the background...

... I heard the ring-road from below, which doesn't have a lot... maybe a little punctuated, but not much, and I call it the belt... the fat belt...

the garden effect

... so, here I've got an opening... but I have another one that is even more beautiful that I call the garden effect... and freedom... the sensation of freedom... and what gave it to me? A bunch of dogs that seemed almost free... country dogs that were doing their own thing... they were barking a little in every direction, and the sound space was animated... something like "ahhh" (breathing)... so here, almost a contradiction in the soundscape compared to the crushing feeling... it was a nice change, to clear my mind...

the echo from the construction site

... I was on the little wooden bench, on the promontory that is at the top... so that's a little elevated... and there, there was today, yesterday too, a small construction site [we will learn that it was in fact Geoklock's site, a society in charge of the neighborhood's environment remediation]... construction workers using their tools, with metallic sounds, there were rods... metallic sounds... and where I was, there was an echo... but not reverberation, though, an echo... an echo effect, of very strong rebound that made me think of an acoustic feeling of confinement...

... so, in conclusion... yes, there are openings... the only real opening is surely given by a soundscape coming from the outside... from the confines... the horizon... and so this impression of being really... in a half-grave... I'm sorry, but that's a very impactful place, very much imbued with death, still...

\section{From felt silence to thickened silence}

The research consisted in gradually thickening the felt silence, in loading it with social, historical and political content, and in associating it with a set of contextual elements that inform it. It was thus not simply a question of sharing an in situ sound experience, but to make explicit the frames around it and the conditions that made the experience possible. Therefore, the study became the building of bridges between the sounds of places and the form of social and material life that underlies them. The joint logbook represents the revelation of the way the sounds are embedded in the neighborhood's social history, in the inhabitants' daily actions, and in the built space's material patterns. If the surrounding silence we were facing borrowed both from the 
action of silencing's taceo and the absence of movement's silencio ${ }^{11}$, it can thus be tackled as a real analyzer of the Condominío's problematic situation and the way to inhabit it. In some way, it is a question of giving silence a voice, and to research what it unveils about this living environment.

This silence, described as voiceless, static or inconsistent, appears like the expression of a way of living that is dominated by the inhabitants' risk and vulnerability. It demonstrates a neighborhood that is left hanging, characterized by a depressive tone. This ambiance reveals the state of a slow motion territory that is coming to a stop, of a living environment that is frozen and left out. With the incomplete state of the ghost-like buildings as the most noticeable trait, the surrounding silence also shows the absence of any internal dynamics. Everything is at a standstill as if time had stopped. We gradually learnt that it was difficult - even forbidden - to develop the condominium's physical structure. For fear of another gas explosion, it was now impossible to cover or rehabilitate the garages, to drill or perforate the ground, to build a collective space, to start new construction works. Moreover, we noted the lack of vegetable garden (contamination of plants and appearance of waste on the ground) and an abandoned basketball court (hardly operable, as it was located in a contaminated area). The development appeared to be stuck, as well as several activities that usually provides rhythm and animation to the local life. This is why the human voices' frugality and the activities' discretion within the condominium tended to produce an inconsistent ambiance, lacking a real internal dynamic, creating a strong influence from the outside's sounds: a very lively neighborhood nearby, a petrochemical hub further away, a busy boulevard and a ceiling of airplanes. We thus can talk about a "pumping" and "paralysis" effect to define this ambiance, which is mainly depressive and struggles to assert itself.

The dwellers' attention bears the mark of hypervigilance and of dispossession. The sound presence from the Geoklock company's works, responsible for the remediation within the condominium, keeps reminding the residents of the state of contamination, and it tends to disrupt the feeling of being at home. The most pregnant and audible sounds from the inside are precisely those produced by people who are not residents of the condominium. Moreover, many inhabitants remember the deadly explosion that took place in 2000. Nowadays, when they hear a sudden sound - a car accident, an unexpected noise by Geoklock or the petrochemical hub - they cannot help but

\footnotetext{
${ }^{11}$ Roland Barthes "The Silence", In The Neutral: Lecture Course at the Collège de France, 1977-1978, New York, Columbia University Press, 2005.
} 
think about the potentiality of another explosion. Everything unfolds as if the inhabitants are on high alert, expecting a forthcoming accident. The risk remains in the residents' collective memory and is a trace in this hypervigilant attention mode. The feeling of strangeness and the disruption of home characterize the ordinary sound experience. The condominium's silence sets itself as the trace of an everyday life that remains problematic and that struggles to be self-evident. Activities as trivial as playing, gardening or tinkering lose their obviousness and keep reminding the inhabitants of their own vulnerability.

Last but not least, the research also taught us about how frustrating, harmful and painful this situation is for the condominium's dwellers. A long-standing struggle has been fought by the inhabitants to uphold their rights, since this situation is hardly bearable day-to-day and causes severe illnesses (children suffering from cancer and depressed residents, sick or ready to leave when they can afford it). This collective disarray struggles to be heard by public forces, and it reveals the lack of expression and vitality that characterizes the neighborhood. Everything comes about as if the silence is the witness of the injunctions and prohibitions that the inhabitants are subjected to, like the various constraints on everyday activities. It is also the expression of the depressive state of a distressed group and the inhabitants' feeling of hopelessness. Furthermore, it is adding to the inhabitants' inability to be heard. ${ }^{12}$ It thus becomes a real analyzer of the controversy that is happening in this contaminated territory.

\section{Conclusion}

This outline of an atmospheric ethnography offers to explore what constitutes a form of social life from the standpoint of its ambiances. The hypothesis is that each way of living, each collective way of being, is embodied and deployed in particular affective tonalities ${ }^{13}$. In other words, a form of social life is always embedded in an

\footnotetext{
${ }^{12}$ At the end of the investigation, Patrick Romieu, one of the French researchers of the team, organized a "big scream", a collective moment in which the inhabitants were gathered to shout, together with the researchers - a big scream from the Condominio's parking lot. This collective performance was both a way to thank the inhabitants for their hospitality and a way to acknowledge their rights to be heard. Silence was momentarily broken.

${ }^{13}$ An abundant literature exists in terms of affective tone, emanating essentially from phenomenology. For an overview of this concept, see Otto Friedrich Bollnow Les
} 
atmospheric way of being, both intertwined. To ignore the social dimension of ambiance would turn the sensory experience into a purely subjective one, and would eventually lead to a solipsistic version of human existence. The sharing of an experience involves first the sharing of an ambiance. Moreover, to omit the atmospheric content of communal life would mean neglecting the ability to be affected by our surroundings and would lead to build a world devoid of any intrinsic vitality. Living together never goes without feeling the atmospheric existence of the world at the same time.

One of the major challenges offered by an atmospheric ethnography is to develop a sensitivity to the tones of situations, to their affective content and their existential value. In that sense, sound is particularly helpful in order to vibrate in accordance to the surrounding world, to get in touch and to resonate with an ambient situation. It could perhaps even present the ultimate medium of an atmospheric attunement. ${ }^{14}$ The silence that we came across in Condominío Barão de Mauá is a perfect example: similar to John Dewey's theory of inquiry, it worked as a diffuse quality that initiated and guided the research from one end to the other. As the expression of an undetermined unrest, this silence made us attentive to the neighborhood's surrounding sounds. It was less about looking for a way to describe a soundscape analytically and more about listening to the situations' tones and the atmospheric effects around everyday behavior. Therefore, we tried to get closer to listening to "significance", at least as much as listening to indexes and signs. ${ }^{15}$ The question was not to identify and catalogue the sounds that we heard, but rather to grasp its gestures and rhythms, the intensities and paces from everyday life which embodied

tonalités affectives. Essai d'anthropologie philosophique. tr. L.\&R. Savioz, Neuchatel, La Baconnière, 1953. The notion of affective tonality enables to go beyond a purely subjective view of emotion and offer an alternative to the object-subject dichotomy. It relates rather to the tone or the overall quality of a situation.

${ }^{14}$ Kathleen Stewart «Atmospheric Attunements», Environment and Planning D: Society and Space. Vol 29, 2011, p. 445-453.

${ }^{15}$ Roland Barthes « Listening 》, In The Responsibility of Forms: Critical Essays on Music, Art, and Representation. Berkeley, California University Press, 1991. The way of listening we developed may also be related to the psychoanalytical listening and the listening with the 'Third Ear': "It is not the words spoken by the voice that are of importance, but what it tells us of the speaker. Its tone comes to be more important than what it tells." Theodor Reik Listening with the Third Ear. New York, Groce Press, 1956, p. 136. 
the living experience. The in situ felt atmospheres were thus the object of a "contextual rebound" aiming at making explicit their frames of existence and the conditions for their appearance.

Deeply exploratory, this sound approach consisted in grasping the interior's tones and in being in tune with the situations we came across. Between distracted listening and focused listening, articulating the doing phase and the undergoing one, it was a question of being available for the emerging sensory and motor phenomena, letting them come and following them in their specific dynamic. The researcher's body thus became a resonator of the site's atmospheric vibrations. ${ }^{16}$ If this atmospheric ethnography indeed involved a work of genuine attention, it was also about implementing a collective learning process on the sensitivity to field work. The communing of everyone's experiences with the help of the joint logbook allowed to broaden our common knowledge of the field, to intensify and multiply the interactions with the inhabitants, and to refine our common ability to listen. This is how our listening never stopped evolving throughout the research, becoming increasingly sensitive to micro-variations and to the small threads that were weaving themselves day after day. ${ }^{17}$ Contrary to the ethnographies that are often carried out in a solitary way, this approach relied from the beginning, and in a constitutive manner, on a common experience evolving in time. The relationship that was growing was not one between a researcher and a group of inhabitants, but rather between two groups that got together based on diverse and varied modalities. In a provisory way, this atmospheric ethnography argues for an art of nuances, attentive to the various tonalities and attunements of social life.

Article translated by Harry Foster and Sophie Provost

\footnotetext{
${ }^{16}$ Relying on William and Henry James, David Lapoujade develops the idea of a resonator as "someone who makes audible the tones in the voices, but also in the places, the things or the atmospheres, the art of the Stimmung." David Lapoujade Fictions du pragmatisme. William et Henry James. Paris, Minuit, 2008, p. 52.

${ }^{17}$ Regarding the approach about small links and attention to nuances in sensory experience in anthropology, see François Laplantine De tous petits liens. Editions Fayard, Mille et une nuits, Paris, 2003.
} 